\title{
Investigating important factors influencing customer relationship management: A case study from banking industry
}

\author{
Ali Sedigh ${ }^{*}$ and Ali Alikhani
}

Department of Management and Accounting, North Tehran branch, Islamic Azad University, Tehran, Iran

\begin{tabular}{|c|c|}
\hline$\overline{C H R O N}$ I CLE & A B S T RACT \\
\hline $\begin{array}{l}\text { Article history: } \\
\text { Received August 16, } 2013 \\
\text { Received in revised format } \\
12 \text { September } 2013 \\
\text { Accepted } 1 \text { November } 2013 \\
\text { Available online } \\
\text { November } 52013 \\
\text { Keywords: } \\
\text { Customer relationship } \\
\text { management } \\
\text { CRM } \\
\text { Banking industry } \\
\text { Information technology }\end{array}$ & $\begin{array}{l}\text { This paper performs an investigation on measuring the effect of different factors on customer } \\
\text { relationship management (CRM) for different branches of an Iranian banks located in various } \\
\text { regions of city of Tehran, Iran. The proposed study selects a sample of } 275 \text { managers and using } \\
\text { structural equation modeling examines the effects of five variables including CRM knowledge, } \\
\text { employment's information technology skills, specialty, strategic use, CRM performance on the } \\
\text { performance of CRM. Cronbach alpha has been calculated for the questionnaire as } 0.881 \text {, which } \\
\text { is well above the minimum acceptable level. The survey has concluded that there were } \\
\text { meaningful relationships between all four mentioned variables and performance of CRM. In } \\
\text { other words, knowledge and information technology influence on improving employments' } \\
\text { skills, which increase strategic use of CRM components and this would improve CRM } \\
\text { performance. }\end{array}$ \\
\hline
\end{tabular}

\section{Introduction}

During the past few years, there have been tremendous efforts on providing value added services for customers through customer relationship management. CRM plays essential role on customer retention especially in banking industry (Nguyen \& Mutum, 2012). Customers are the primary sources of making suitable decisions and their feedbacks normally help us improve the quality of systems (Sophonthummapharn, 2009). Banking industry in Iran has been under pressure through emerging the newly established private banks. There are literally many studied associated with the the effect of CRM on the success on banking industry. Manesh and Hozouri (2013) used factor analysis to extract important factors influencing CRM in banking industry and reported nine factors including customers' welfare strategy, systems integration, organizational culture assessment, corporate strategies, organizational development, intelligence data strategies, supporting strategies, resource

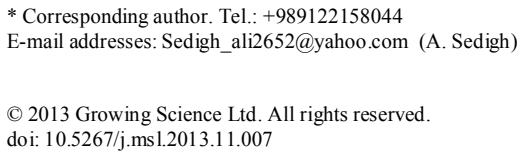


planning as well as research and development. Information technology (IT) is one of the most influential factors on the success of CRM implementation.

Bahrami et al. (2012) investigated the effects of IT implication on the success of CRM implementation. Chang et al. (2010) discussed how CRM could make significant change on the performance of most organizations. Garrido-Moreno and Padilla-Meléndez (2011) analyzed the effect of knowledge management on CRM success by looking into various mediating effects of organizational factors. Ko et al. (2008) studied the effects of organizational characteristics on the CRM adoption process. Li and Mao (2012) studied the effect of CRM implementation on internal sales management control by investigating an alternative mechanism to realize CRM advantages. Azad et al. (2014) performed an empirical investigation to detect important factors influencing CRM in information and communication firm in Iran. The survey applied factor analysis to detect important factors using a questionnaire consist of 27 variables and detected six factors influencing CRM learning performance attributes, enterprise resource planning, perception attributes, structure oriented, perception image and organizational resources. Hakkak et al. (2012) studied the role of CRM in improving organizational effectiveness on customers for one of Iranian bank called Agricultural. The results of their survey disclosed that all these mentioned factors could impact customer satisfaction, positively.

\section{The proposed model}

This paper performs an investigation on measuring the effect of different factors on customer relationship management (CRM) on different branches on an Iranian banks located in various regions of city of Tehran, Iran. Fig. 1 demonstrates the proposed study of this paper.

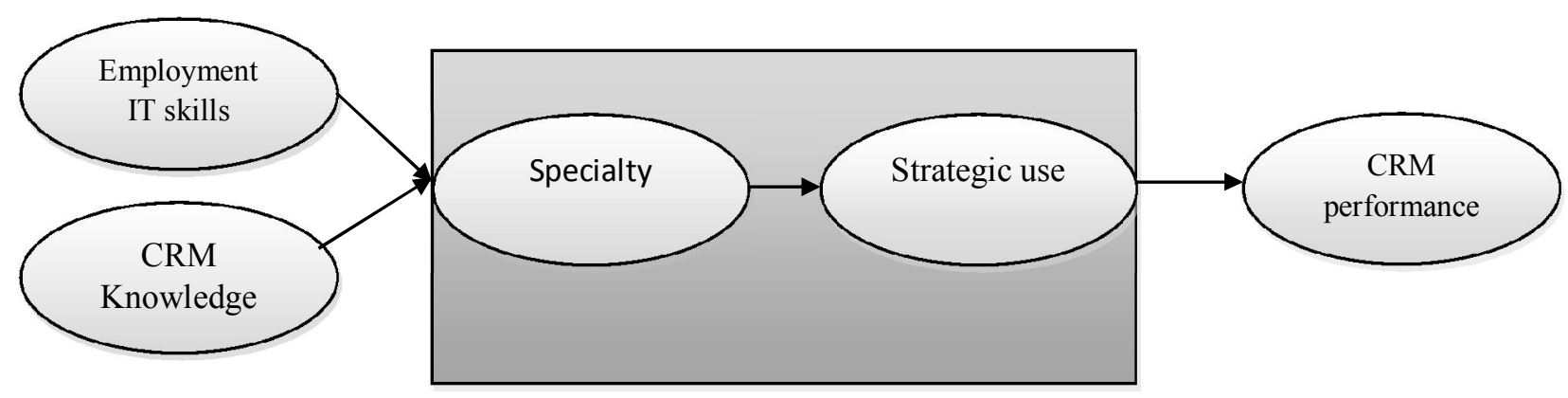

Fig. 1. The proposed study

As we can observe from Fig. 1, Employment's IT skills as well as CRM knowledge influence existing specialty and this would influence strategic use. These factors, together, will influence CRM performance. The proposed study designs a questionnaire and distributes it among some randomly selected managers who work for bank Maskan in city of Tehran, Iran. There were 960 people were working for this bank and the proposed study selects the sample size as follows,

$n=\frac{N \times z_{\alpha / 2}^{2} \times p \times q}{\varepsilon^{2} \times(N-1)+z_{\alpha / 2}^{2} \times p \times q}$,

where $N$ is the population size, $p=1-q$ represents the yes/no categories, $z_{\alpha / 2}$ is CDF of normal distribution and finally $\varepsilon$ is the error term. Since we have $p=0.5, z_{\alpha / 2}=1.96$ and $N=960$, the number of sample size is calculated as $n=275$. In our survey, $27.2 \%$ of the participants were female and $72.6 \%$ of them were male. In addition, $24 \%$ of the participants were single and $76 \%$ of them were married. Fig. 2 shows details of their job experiences and educational backgrounds. 


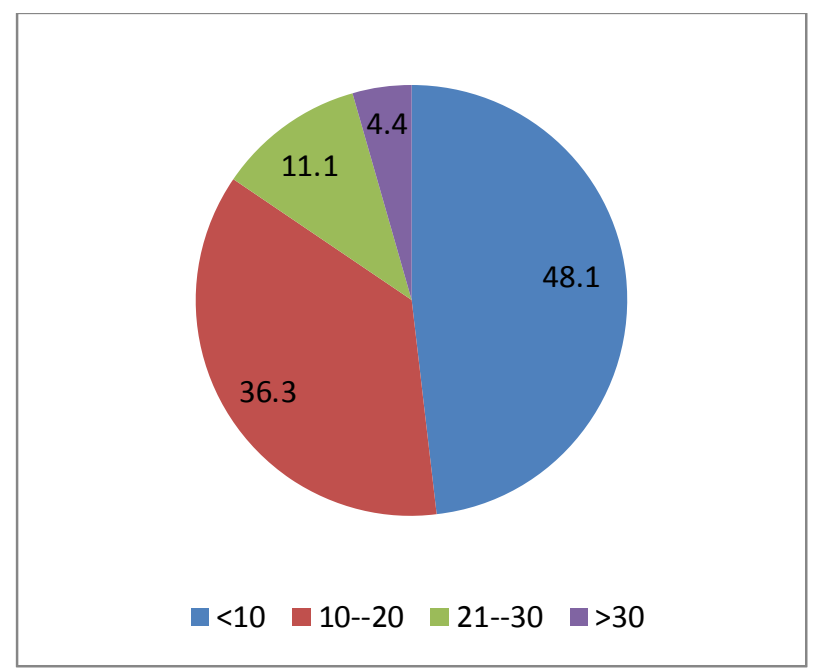

Job experiences

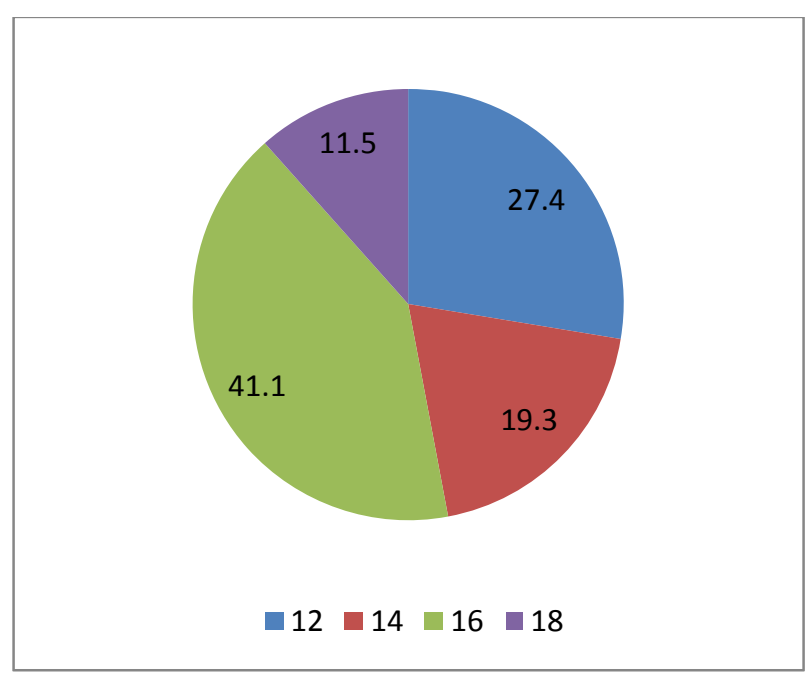

Years of educations

Fig. 2. Personal characteristics of the participants

As we can observe from the results of Fig. 2, nearly half of the participants had fewer than 10 years of job experiences while $36.3 \%$ of them had between 10 to 20 years of job experiences. In addition, over $78 \%$ of the people who took part in our survey had some university educations. The study designs the questionnaire in Likert scale, where 12 questions were associated with CRM knowledge, 3 questions were related to IT skills, 3 questions were devoted to specialty, 5 questions were associated with strategic use and 4 questions were related to CRM performance. The proposed study uses structural equation modeling to examine the effects of five variables including CRM knowledge, employment's information technology skills, specialty, strategic use, CRM performance on the success of CRM. Table 1 summarizes the results of Cronbach alphas for various components of the survey.

\section{Table 1}

The summary of Cronbach alpha

\begin{tabular}{lc}
\hline Attribute & Cronbach alpha \\
\hline Knowledge CRM & 0.866 \\
Employment IT skills & 0.803 \\
Specialty & 0.841 \\
Strategic use & 0.766 \\
CRM performance & 0.801 \\
\hline Total & 0.881 \\
\hline
\end{tabular}

As we can observe from the results of Table 1, all Cronbach alphas are well above the minimum desirable level of 0.70 , which validates the overall questionnaire.

\section{The results}

In this section, we present details of our findings on testing various hypotheses of this survey. Fig. 3 shows details of our findings on the results of structural equation modeling. As we can see from the results of Fig. 3, the result of Chi-Square/df is equal to 2.033, which is less than desirable level of 3, GFI is equal to $0.91>0.90$, RMSEA is equal to 0.062 , which is less than 0.09 . In addition, the values of CFI, NFI, NNFI and IFI are equal to $0.98,0.97,0.98$ and 0.96 , respectively and they are above the desirable level of 0.90 . These results indicate that we could rely on the results of our investigation. Table 2 shows details of our survey on testing various hypotheses of the survey. 


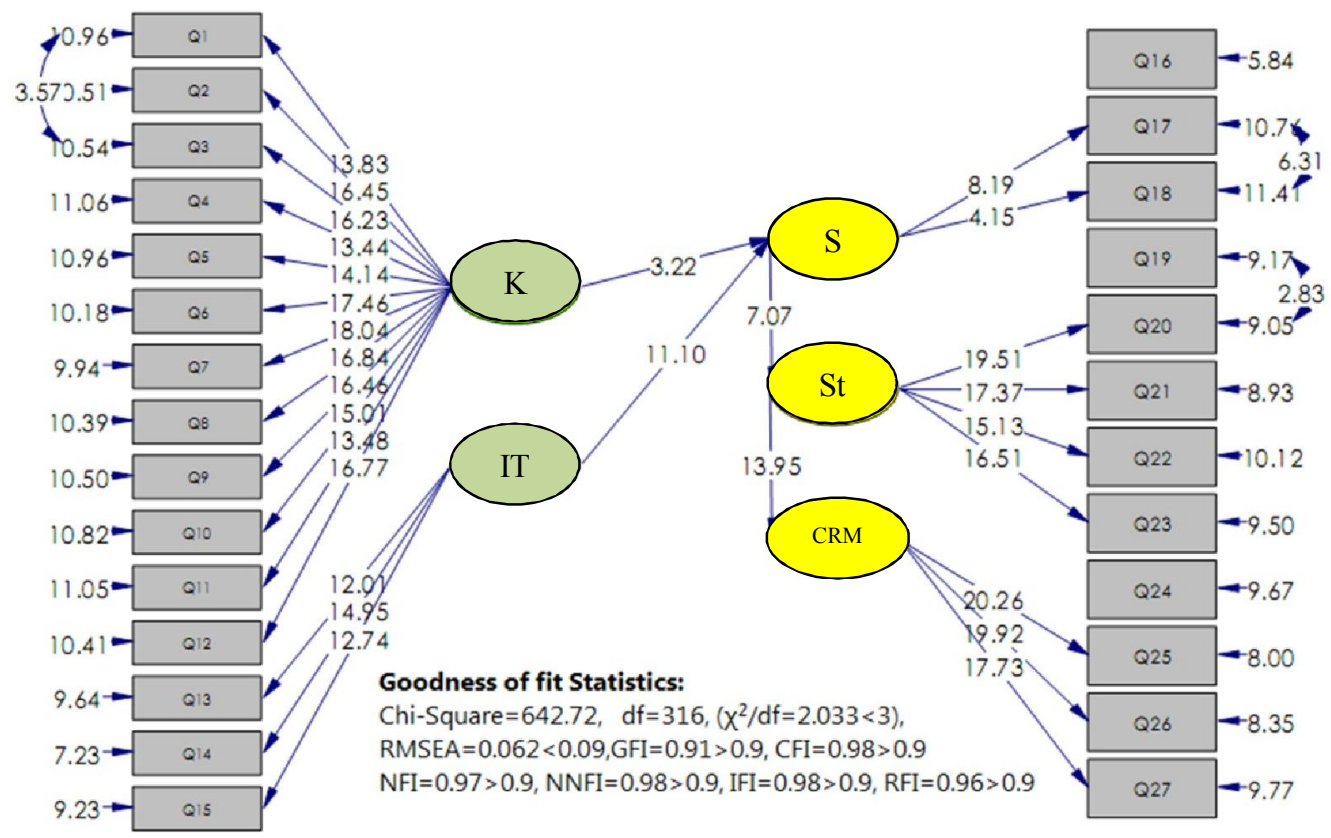

K: Knowledge, IT: IT skills, S: Specialty, St: Strategic use, CRM: CRM performance

Fig. 3. The results of t-student values for structural equation modelling

Table 2

The summary of testing various hypotheses

\begin{tabular}{lccccc}
\hline Path & $\beta$ & $\mathrm{t}$ & $\begin{array}{c}\text { Coefficient } \\
\text { determination }\end{array}$ & Sig. & Result \\
\hline Knowledge CRM $\rightarrow$ Specialty & 0.20 & 3.22 & 0.87 & 0.000 & $\sqrt{ }$ \\
Employment IT skills $\rightarrow$ Specialty & 0.81 & 11.1 & 0.87 & 0.000 & $\sqrt{ }$ \\
Knowledge CRM $\rightarrow$ Specialty $\rightarrow$ Strategic use & 0.097 & 2.99 & 0.21 & 0.000 & $\sqrt{ }$ \\
Employment IT skills $\rightarrow$ Specialty $\rightarrow$ Strategic use & 0.39 & 6.57 & 0.21 & 0.000 & $\sqrt{ }$ \\
Specialty $\rightarrow$ Strategic use & 0.49 & 7.07 & 0.24 & 0.000 & $\sqrt{ }$ \\
Strategic use $\rightarrow$ CRM performance & 0.87 & 13.95 & 0.72 & 0.000 & $\sqrt{ }$ \\
\hline
\end{tabular}

The results of Table 2 clearly confirm all hypotheses of the survey.

3.1. The first hypothesis: The effect of employment's IT skills on strategic CRM use via CRM specialty

The first hypothesis of this survey is associated with the relationship between employment's IT skills and strategic CRM use through specialty. According to the results of Table 2, the path coefficient is equal to 0.39 and t-student value equal to 6.57 and the result is statistically significance with $\alpha=5 \%$. Therefore, we confirm the first hypothesis of this survey.

\subsection{The second hypothesis: The effect of employment's CRM knowledge on strategic CRM use via} CRM specialty

The second hypothesis of this survey is associated with the relationship between employment's CRM knowledge and strategic CRM use through CRM specialty. According to the results of Table 2, the path coefficient is equal to 0.097 and t-student value equal to 2.99 and the result is statistically significance with $\alpha=5 \%$. Therefore, we confirm the second hypothesis of this survey. 


\subsection{The third hypothesis: The effect of CRM technology on CRM performance}

The third hypothesis of this survey is associated with the relationship between CRM technology and CRM performance. Based on the result of Table, the path coefficient is equal to 0.87 and t-student value of 13.95, which indicates a strong and positive relationship between these two components. Therefore, we can confirm the third hypothesis of this survey.

\subsection{The fourth hypothesis: The effect of specialty on strategic use of CRM}

The last hypothesis of this survey studies the relationship between employment's specialty and strategic use of CRM. Based on the result of Table, the path coefficient is equal to 0.49 and t-student value of 7.07, which indicates a strong and positive relationship between these two components. Therefore, we can confirm the third hypothesis of this survey.

\section{Conclusion}

During the past few years, there have been tremendous efforts on providing value added services for customers through customer relationship management. CRM plays essential role on customer retention specially in banking industry. Banking industry in Iran has been under pressure through emerging the newly established banks. In this paper, we have presented an empirical investigation to study the effect of CRM on performance of the banking industry. The survey has concluded that there were meaningful relationships between all four mentioned variables and performance of CRM. In other words, knowledge and information technology influence on improving employments' skills, which increase strategic use of use of CRM components and this would improve CRM performance.

\section{Acknowledgement}

The authors would like to thank the anonymous referees for constructive comments on earlier version of this paper. We also appreciate managers of Bank Maskan for cordially cooperating on accomplishment of this paper.

\section{References}

Azad, N., Roshan, A \& Hozouri, S. (2014). An exploration study on influential factors on customer relationship management. Decision Science Letters, 3(1), 49-56.

Bahrami, M., Ghorbani, M., \& Arabzad, S. M. (2012). Information technology (IT) as an improvement tool for customer relationship management (CRM). Procedia-Social and Behavioral Sciences, 41, 59-64.

Chang, W., Park, J. E., \& Chaiy, S. (2010). How does CRM technology transform into organizational performance? A mediating role of marketing capability. Journal of Business Research, 63(8), 849855.

Garrido-Moreno, A., \& Padilla-Meléndez, A. (2011). Analyzing the impact of knowledge management on CRM success: The mediating effects of organizational factors. International Journal of Information Management, 31(5), 437-444.

Hakkak, M., Esmaeili, M \& Mirzaei, M. (2012). An investigation on role of customer relationship management (CRM) in increasing organizational effectiveness. Management Science Letters, 2(8), 2827-2832.

Ko, E., Kim, S. H., Kim, M., \& Woo, J. Y. (2008). Organizational characteristics and the CRM adoption process. Journal of Business Research, 61(1), 65-74.

Li, L., \& Mao, J. Y. (2012). The effect of CRM use on internal sales management control: An alternative mechanism to realize CRM benefits. Information \& Management, 49(6), 269-277.

Manesh, F \& Hozouri, S. (2013). How customer relationship management influences making better decisions. Management Science Letters, 3(11), 2767-2774. 
Nguyen, B., \& Mutum, D. S. (2012). A review of customer relationship management: successes, advances, pitfalls and futures. Business Process Management Journal, 18(3), 400-419.

Sophonthummapharn, K. (2009). The adoption of techno-relationship innovations: a framework for electronic customer relationship management. Marketing Intelligence \& Planning, 27(3), 380-412. 